\title{
Microstructural change in ice: I. Constant-deformation-rate tests under triaxial stress conditions
}

\author{
P. M. Melanson, I. L. Meglis, ${ }^{*}$ I. J. Jordaan, B. M. Stone \\ Ocean Engineering Research Centre, Faculty of Engineering and Applied Science, Memorial University of Newfoundland, \\ St John's, Newefoundland AlB 3X5, Canada
}

\begin{abstract}
Extensive damage to ice occurs during ice structure interaction by microcracking, recrystallization and melting. The objective of this work was to investigate this damage process under confined-stress conditions believed to be associated with impact zones that occur during ice-structure interaction. "Damage" refers to microstructural modification that causes deterioration of the mechanical properties. Prior experimental work has shown that a small amount of deformation causes permanent damage in ice, leading to enhanced creep rates during subsequent loading. To investigate this softening, freshwater granular ice was deformed under moderate confinement $(20 \mathrm{MPa})$ at $-10^{\circ} \mathrm{C}$, at two rates which bracket ductile and brittle behavior $\left(10^{-2} \mathrm{~s}^{-1}\right.$ and $\left.10^{4} \mathrm{~s}^{1}\right)$. Samples were deformed to different levels of axial strain up to $28.8 \%$. Thin sections were examined to assess the progressive changes in microstructure.

Both grain-boundary and intra-granular cracking began at strains corresponding to the peak stress $(1-2 \%)$ for tests at both strain rates. The peak stresses were 23.4 MPa for the tests at $10^{-2} \mathrm{~s}^{-1}$ and $9.8 \mathrm{MPa}$ for the tests at $10^{-4} \mathrm{~s}$. At strains of $>1-2 \%$, dense clusters of intra-granular cracks began to develop in the samples tested at the higher rate. At the lower rate, dynamic recrystallization was apparently the dominant deformation mechanism beyond the peak stress. The average grain-size decreased strongly during the first few per cent strain and then maintained a relatively stable value.
\end{abstract}

\section{INTRODUCTION}

Research in ice mechanics at the Ocean Engineering Research Centre of Memorial University of Newfoundland has focused on understanding the deformation of ice during impact with offshore structures. The objective of this research is to develop models for ice structure interaction to aid in the design of offshore structures and vessels that are subject to impacts with ice in arctic and subarctic waters.

The load acting on structures during an ice impact event is transmitted through localized, short-lived zones of intense high pressure at the interaction interface. For example, in ship-ramming trials on sea ice with the icebreaker CGGS Louis S. St Laurent, numerous local peaks in pressure were recorded on the hull during contact. The largest peak pressure was as high as $53 \mathrm{MPa}$ on a sensor $7.94 \mathrm{~mm}$ in diameter. The average value of all the peaks over the course of the interaction was $27 \mathrm{MPa}$ (Glen and Blount, 1984). These peaks lasted $0.01-0.1 \mathrm{~s}$. Medium-scale indentation tests on Hobson's Choice ice island have shown peak pressures as high as $70 \mathrm{MPa}$ on sensors $12.7 \mathrm{~mm}$ in diameter (Frederking and others, 1990; Johnston and others, in press ). These high stresses result in the formation of a damaged layer of ice in the contact zone, as seen in field tests (Kheisin and Cherepanov,

\footnotetext{
* Present address: Department of Physics, University of Alberta, Edmonton, Alberta T6G 2J1, Canada.
}

1973; Kennedy and others, 1994). High-pressure zones are discussed in more detail in the next section.

Because high-pressure zones are responsible for transmitting a large fraction of the total load applied to a structure, understanding the mechanics of ice under these stress conditions is a necessary component in predicting impact loads. The goal of the work presented in this and the accompanving papers (Meglis and others, 1999; Muggeridge and Jordaan, 1999) is to characterize damage and microstructural change in ice under high-pressure-zone conditions, both in the field and in the laboratory. This work is being used in the development of constitutive relations for ice (Melanson, 1998; Jordaan and others, 1999).

Previous experimental work has examined the effects of damage on the mechanical behavior of ice (Stone and others, 1989; Jordaan and others, 1992). Results from triaxial testing by Stone and others (1997) have shown that enhanced creep rates occur in ice that has been subjected to prior damage as a consequence of a small axial strain applied at a rate of $10^{-4} \mathrm{~s}^{-1}$. Following those results, the objective of the work presented in this paper was to characterize the progressive microstructural change produced by an imposed axial strain. The effects of varying both the strain rate and the level of axial strain have been investigated. Work by Melanson (1998), presented in the accompanying paper (Meglis and others, 1999), demonstrates how such damage can influence the subsequent creep behavior of ice. These data are required in order to understand the mechanisms for the softening and failure of ice due to damage under the range of stress conditions associated with high-pressure zones. 


\section{BACKGROUND}

\section{High-pressure zones}

The contact zone between an ice feature and a structure is characterized by regions of high pressure that develop within and behind a severely damaged crushed layer at the interaction interface (see Fig. 1). The layer has been reported to be from a few $\mathrm{mm}$ to $170 \mathrm{~mm}$ or more in thickness (Meaney and others, 1991), but is typically about $40 \mathrm{~mm}$ in indention tests where the contact area is about $1 \mathrm{~m}^{2}$. Strain rates associated with these interactions in the field can approach $1 \mathrm{~s}^{-1}$, and may be even higher directly within the damaged layer.

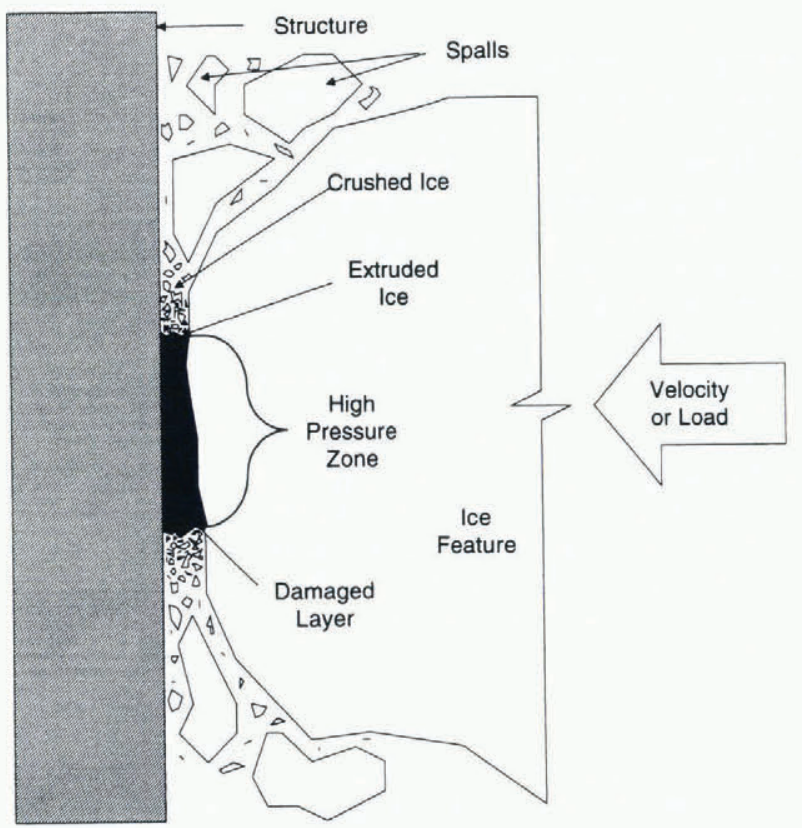

Fig. 1. Schematic showing elements of ice-structure interaction.

High-pressure zones are the source of the crushed ice that has been observed to be extruded from the indentor interface during field indentation tests (Meaney and others, 1991). Spalling also occurs during an interaction, both resulting from and contributing to the occurrence of local high pressures. The high-pressure zones exist for only fractions of a second and vary in both space and time, appearing and disappearing within the interaction zone as the ice is crushed and deformed. A large pressure gradient at the edge of the zones results in areas of high shear stress near the outer boundaries. High-pressure zones are responsible for transmitting a large fraction of the load to the structure, estimated at $>90 \%$ by Johnston and others (in press). Oscillations in load have been observed in ice structure interactions and field testing, and have been interpreted as reflecting the clearing and extrusion of crushed ice from the interface as the indentor or structure moves forward.

In the present study the change in the microstructure within the ice is observed. In particular, testing has been done under stress conditions believed to be associated with the breakdown of the intact parent ice into the highly damaged, soft ice found in the layer at the ice-structure interface.

\section{Damage mechanics}

Dramatic microstructural changes occur in ice under stress that are reflected in the mechanical properties and behavior of the material. Damage is defined, for the present purposes, as a microstructural change which produces softening or weakening of the material. It is generally quantified using state variables of scalar or tensor form, representing, for example, the density of flaws (Kachanov, 1997); for viscoelastic materials, methods based on the principles of irreversible thermodynamics (Schapery, 1981) are appropriate. Microstructural changes in the material that result in the loss of strength are typically of the following kind: void formation, cracking, dislocation pile-ups and changes in grain-size. Damage mechanics has been applied to the deformation of polycrystalline ice by Jordaan and McKenna (1988, 1991) and Karr and Choi (1989), among others.

Previous investigations of damage in ice have focused on microcracking, under both uniaxial and triaxial conditions (Kuehn and others, 1988; Stone and others, 1989; Jordaan and others, 1992; Jordaan and Xiao, 1993; Rist and Murrell, 1994). Stone and others (1997) have shown that dynamic recrystallization is also a mechanism of softening at higher stress levels, leading to greatly enhanced creep rates. Pressure melting is also associated with damage and microstructural change under impact conditions (Kheisin and Cherepanov, 1973). Under conditions where high pressures exist, damage can result from all of these mechanisms. Microcracking will occur particularly in regions of high shear stress with low confinement. At higher confinement levels, cracking is suppressed and softening is associated with the occurrence of dynamic recrystallization.

Although pressure melting is a softening mechanism, it may also act to reduce damage under some conditions (e.g. by healing cracks and melting grains). A pressure of $110 \mathrm{MPa}$ will cause melting at $-10^{\circ} \mathrm{C}$ (Nadreau and Michel, 1987; Nordell, 1990). Since pressures of $70 \mathrm{MPa}$ have been observed under field conditions (Frederking and others, 1990), and pressures on the order of $50 \mathrm{MPa}$ are not uncommon, the effects of localized stress concentrations of these applied loads could be sufficient to initiate melting during ice-structure interaction at grain boundaries. Jordaan and others (1999) have proposed that areas of stress concentrations (particularly grain boundaries) could recrystallize or melt and then refreeze, thereby relieving the local stresses and transferring them to other regions.

Previous studies on triaxial testing of ice have contributed to an understanding of the behavior of ice under confinement. Jones (1982) showed that the strength of ice is pressure-dependent at strain rates above $10^{-5} \mathrm{~s}^{-1}$, where crack nucleation can be suppressed. However, this strengthening effect is limited to approximately the first $20 \mathrm{MPa}$ of confinement. Jones (1982) also discusses the effects of pressure melting as a result of high stresses at the grain boundaries, causing softening of the material at higher pressures. A study on microcracking and its effects on the stress-strain behavior of ice at varying confining pressures was reported by Rist and others (1994). Moderate confinement, while reducing the extent of microcracking, was reported to have little effect on the shear strength of the ice in that study. Others have investigated the effects of constant strain rate or constant deformation rate, both at low rates (Mellor and Cole, 1982) and at high rates (Rist and others, 1988; Kalifa and others, 1992). Rist and others (1988) reported on work similar to that presented in this study, but at a lower temperature of $-20^{\circ} \mathrm{C}$, and over a varying range of confining pressures. The results showed a range of failure and deformation mechanisms from crack propagation to creep as con- 
finement was increased. Kalifa and others (1992) showed the pressure dependence of microcracking as well as a change in failure of the ice from brittle to ductile with the application of confinement. Only a few studies have focused on characterizing the microstructural changes to the samples as a result of such testing. For example, in Jacka and Maccagnan (1984) uniaxial test specimens showed a systematic change in both grain-size and grain orientation with increasing strain.

The objective of the present study was to examine and compare the progressive microstructural changes in specimens tested at two different strain rates under moderate confinement. Following previous work by Stone and others (1997), these tests were aimed at imposing fixed amounts of strain on ice specimens. Specimens of granular fresh-water ice were deformed at a constant rate (corresponding to a nominal axial strain rate of either $10^{-4} \mathrm{~s}^{-1}$ or $10^{-2} \mathrm{~s}^{-1}$ ) under moderate confinement $(20 \mathrm{MPa})$ to end-levels of axial strain ranging from $0.4 \%$ to $28.8 \%$ true strain. The progressive change in microstructure with increasing strain was characterized in thin sections obtained from test specimens

\section{PROCEDURE}

\section{Sample preparation}

Blocks of monocrystalline ice were moulded using distilled and deaerated water. The ice was then crushed and sieved between $2.00 \mathrm{~mm}$ and $3.36 \mathrm{~mm}$ sized mesh. The crushed ice was placed in an acrylic mould which was then evacuated, flooded with distilled and deaerated water under vacuum and allowed to freeze slowly over several days. Four cylindrical samples $155 \pm 0.2 \mathrm{~mm}$ in length and $70 \pm 0.05 \mathrm{~mm}$ in diameter were machined from each granular ice block. Blocks of ice adjacent to the ends of the cylinders were stored for later thin-section analysis of the undamaged material. The machined samples were stored at $-15^{\circ} \mathrm{C}$ until the day prior to testing.

\section{Test procedure}

Samples were allowed to equilibrate for at least 12 hours at $-10^{\circ} \mathrm{C}$ prior to being tested with a Materials Testing Systems (MTS) test frame fitted with a Structural Behaviour Engineering Laboratories Model 10 triaxial cell. The MTS system consisted of two servo-controlled hydraulic rams that applied axial load and confining pressure independently. The rams were controlled using MTS TestStar II software, operated on an OS/2-based 486 computer. The computer and software also performed data acquisition for each test. A diagram of the MTS testing system is shown in Figure 2.

A prepared sample was mounted on hardened-steel end platens of the same diameter, and the assembly was then enclosed in a latex jacket to exclude the confining medium (silicone oil). The specimen assembly was then placed inside the triaxial cell, and two linear variable differential transformers (LVDTs) were clamped to the sides of the jacketed specimen. In the tests to low strain levels, the LVDTs were used to monitor axial displacement and to control the advance rate of the ram. For tests to high strain levels, large sample distortions prevented the use of LVDTs. In these tests, the displacement of the ram was used to control the ram advance rate directly.

The confining cell was closed and filled with silicone oil, and a small axial load was applied at ambient pressure to

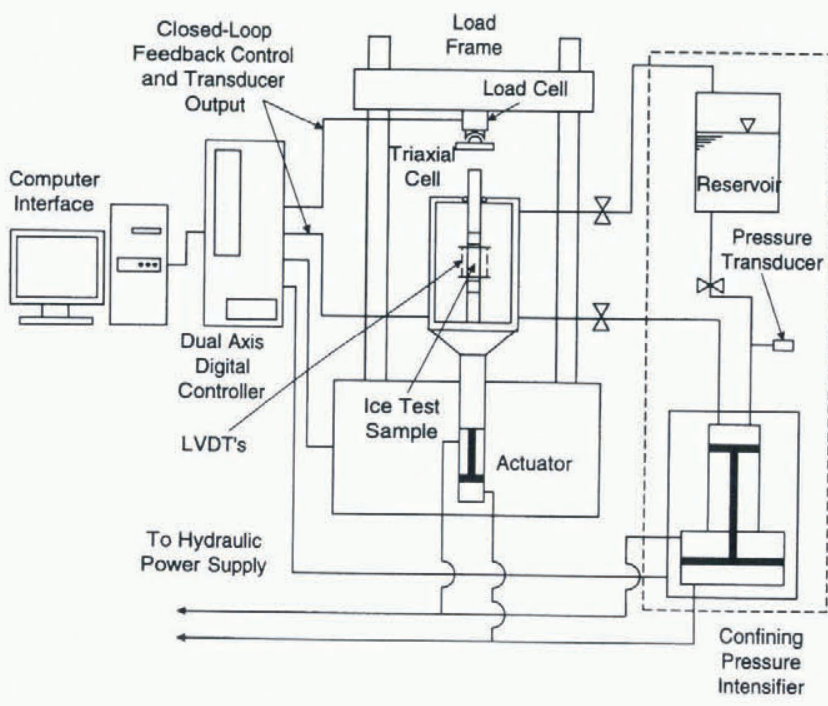

Fig. 2. Schematic of MTS system and triaxial cell.

ensure contact between the specimen and piston. The confining pressure was then increased at $0.5 \mathrm{MPa} \mathrm{s}^{-1}$ to $20 \mathrm{MPa}$, and the axial deformation applied to the sample. Table 1 summarizes the tests performed. At the end of each test the axial load was quickly removed and the confining pressure was then released gradually. The sample was removed from the cell immediately after testing and inspected for jacket leaks and large-scale fracture. When immediate thin sectioning was not possible, samples were stored at $-30^{\circ} \mathrm{C}$ to inhibit grain growth and other microstructural change until thin sections could be prepared and photographed.

Table 1. Test matrix

\begin{tabular}{cc}
\hline $\begin{array}{c}\text { Total axial strain } \\
\%\end{array}$ & $\begin{array}{c}\text { Strain rate } \\
\mathrm{s}^{-1}\end{array}$ \\
\hline 0.4 & $10^{-2}$ \\
0.7 & $10^{-2}$ \\
1.0 & $10^{-2}$ \\
2.0 & $10^{-2}$ \\
4.1 & $10^{-2}$ \\
12.8 & $10^{-2}$ \\
28.8 & $10^{-2}$ \\
& \\
0.4 & $10^{-4}$ \\
0.8 & $10^{-4}$ \\
1.0 & $10^{-4}$ \\
1.4 & $10^{-4}$ \\
2.0 & $10^{-4}$ \\
4.1 & $10^{4}$ \\
12.8 & $10^{-4}$ \\
28.8 & $10^{-4}$ \\
\hline
\end{tabular}

\section{Sample and data analysis}

Thin sections were generally prepared within 2 hours of testing. Sections of the ice were cut both parallel and perpendicular to the longitudinal axis of the cylindrical samples. To preserve the microstructure, sections were welded to glass plates using a thin bead of water around the perimeter of the specimen rather than melted on. The surfaces of the sections were polished on both sides using a microtome.

Thin sections were photographed at two magnifications under three different lighting conditions. The lighting conditions were: (a) the thin section between crossed polarizing 
filters, (b) the thin section between crossed polarizing filters with side lighting, and (c) with side lighting only. Each of these three modes highlighted different microstructural characteristics. Viewed between crossed polarizing filters, the grain structure is emphasized. With additional side lighting, cracks and voids can be seen in relation to the grain structure. With the thin sections illuminated only from the side, cracks, bubbles and voids can be seen most clearly. Samples from some of the earliest tests were not photographed in all three modes.

Long, parallel cracks seen in some thin sections resulted from the thin-sectioning process. These are easily distinguished from the grain-scale cracks associated with the deformation. Average grain-size was determined from thin sections cut normal to the long axis of the sample. Using the mean-intercept-length method outlined in Dieter (1976), the number of grains intercepted by a test line was counted and then divided by the total length of the line. This method generally underestimates the true diameter of equi-axed grains. However, it is a straightforward method for determining relative differences in average grain-size.

\section{Stress correction for lateral strain}

For the tests taken to high levels of axial strain, the increasing cross-sectional area resulting from lateral strain causes a decrease in the actual deviatoric stress within the sample. The difference between the nominal and the actual stress is most significant for the samples subjected to the largest amounts of strain: at $45 \%$ axial strain, the estimated stress acting on the increased sample area decreases to approximately $65 \%$ of the nominal stress. A correction to the deviatoric stress to account for this lateral strain was therefore made by assuming constant volume deformation and a uniform increase in sample cross-sectional area with axial strain. This approximation correlates well with diameters measured from thin sections following testing.

\section{RESULTS}

\section{Microstructural observations}

Photographs of a horizontal thin section from a typical undamaged (undeformed) ice specimen are shown in Plate $1^{*}$. The average grain-size for the undeformed specimens was $2.38 \mathrm{~mm}$. No obvious preferred $c$-axis orientation was visible and only a few small air bubbles were observed. The undamaged ice showed no microfracturing as a result of grain growth, thermal effects or the thin-sectioning process. The scales shown in all the thin-section photographs are in $\mathrm{mm}$.

A selection of horizontal thin sections is shown in Plates 2 and 3 from the two series of tests done at different strain rates. These figures show a photograph of the section between crossed polarizing filters (left view) and a photograph with either side lighting or side lighting with crossed polarizing filters, if available (right view). These series of photos highlight the progressive microstructural changes in the samples with increasing axial strain.

\section{Stress-strain behavior}

Stress-strain curves are shown in Figure 3 for representative

\footnotetext{
* For colour plates see section following this paper.
}

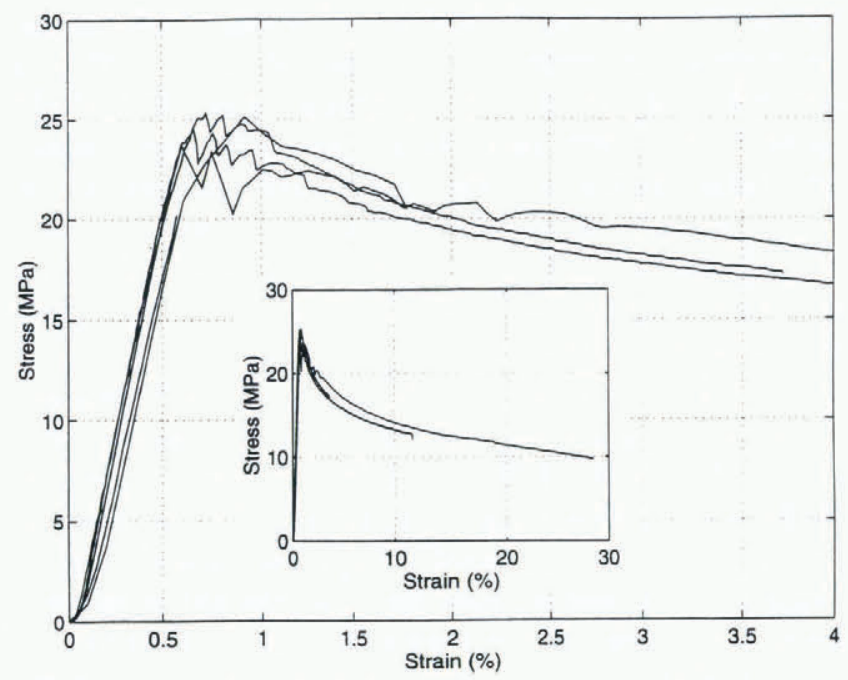

Fig. 3. Corrected stress vs true axial strain for tests at a strain rate of $10^{-2} \mathrm{~s}^{-1}$.

tests performed at a nominal strain rate of $10^{-2} \mathrm{~s}^{-1}$, using the deviatoric stress corrected for increasing cross-sectional area, as discussed. A similar set of curves is shown in Figure 4 for the tests at a strain rate of $10^{-4} \mathrm{~s}^{-1}$. The stress-strain curves for the tests not shown were similar in both shape and peak stress. The similarity between the curves indicates the reproducibility of the tests.

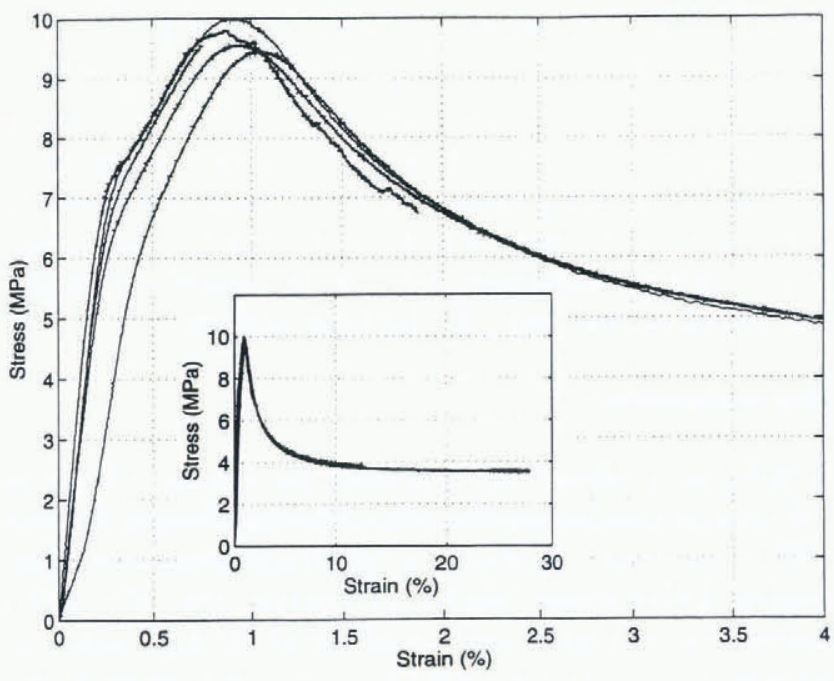

Fig. 4. Corrected stress vs true axial strain for tests at a strain rate of $10^{-4} \mathrm{~s}^{-1}$.

At a strain rate of $10^{-4} \mathrm{~s}^{-1}$ the peak stress averaged 9.3 $\mathrm{MPa}$. At a strain rate of $10^{-2} \mathrm{~s}^{-1}$ the peak stress averaged $23.4 \mathrm{MPa}$. In all cases the peak stress occurred between $0.8 \%$ and $1.2 \%$ axial strain. These peak stress values are consistent with results from other researchers (Jones, 1982). A significant difference between the responses of the ice at the two strain rates is the occurrence of stress fluctuations near the peak in the high-strain-rate tests. Observations of the thin sections from the higher-strain-rate tests suggest that this is related to the formation of grain-boundary and isolated intra-granular cracks, which dominate the microstructure at these strain levels.

The stresses in both tests appear to be approaching a steady state once the peak stress is passed. The higherstrain-rate tests (which represent only a fraction of the time 
spanned by the low-strain-rate tests) did not reach a steady state, as indicated by continuing decline in stress even at the end of the test (Fig. 3). The stresses at $12.8 \%$ and $28.8 \%$ axial strain are 13.0 and $9.8 \mathrm{MPa}$, respectively. In tests at the lower strain rates the stress stabilizes at $3.5-4 \mathrm{MPa}$. At a strain rate of $10^{-4} \mathrm{~s}^{-1}$, the stresses are 3.8 and $3.6 \mathrm{MPa}$ at $12.8 \%$ and $28.8 \%$ axial strain, respectively.

\section{Grain-size}

Grain-size showed an overall decrease with increasing axial strain for tests at both strain rates. Grain-size values are plotted against the total strain for each sample in Figure 5 and are also summarized in Table 2. The initial grain-size averaged $2.38 \mathrm{~mm}$. With as little as $4 \%$ axial strain, the average grain-size dropped to $<1 \mathrm{~mm}$ for tests at both strain rates. The grain-size remained fairly stable at strain levels of $>4 \%$, dropping only slightly to $0.90 \mathrm{~mm}$ at $28.8 \%$.

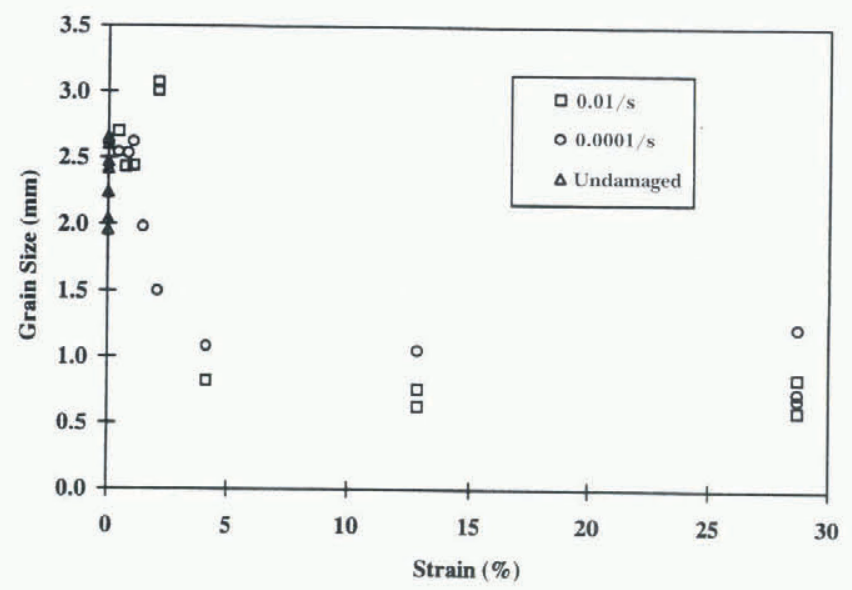

Fig. 5. Average grain-size vs total axial strain for all tests.

In the specimens subjected to strains of $>1 \%$, the grain texture was modified significantly, with a few relatively large grains $(>5 \mathrm{~mm}$ diameter) surviving as remnants within a matrix of very fine grains $(<1 \mathrm{~mm}$ diameter). Plates $2 \mathrm{~b}$ and $\mathrm{c}$ and $3 \mathrm{~b}$ show examples of this texture.

Table 2. Average grain-size for samples at each strain level

\begin{tabular}{ccc}
\hline Total axial strain & Strain rate & Average grain diameter \\
$\%$ & $s^{-1}$ & $\mathrm{~mm}$ \\
\hline 0.4 & $10^{-2}$ & 2.70 \\
0.7 & $10^{-2}$ & 2.43 \\
1.0 & $10^{-2}$ & 2.44 \\
2.0 & $10^{-2}$ & 3.04 \\
4.1 & $10^{2}$ & 1.14 \\
12.8 & $10^{-2}$ & 0.6 \\
28.8 & $10^{-2}$ & 0.9 \\
0.4 & $10^{-4}$ & 2.54 \\
0.8 & $10^{-4}$ & 2.53 \\
1.0 & $10^{-4}$ & 2.62 \\
1.4 & $10^{4}$ & 1.98 \\
2.0 & $10^{-4}$ & 1.50 \\
4.1 & $10^{-4}$ & 1.08 \\
12.8 & $10^{-4}$ & 1.05 \\
28.8 & $10^{4}$ & 0.96 \\
Undeformed & $\mathrm{n} / \mathrm{a}$ & 2.38 \\
& & \\
\hline
\end{tabular}

\section{Microcracking}

Extensive cracking occurred in the samples tested at the higher strain rate, as seen in Plate 2. Fewer cracks were present in samples tested at the lower strain rate, found primarily in the sample deformed to $1.0 \%$ strain (Plate 3a). At both strain rates, this cracking generally began to occur near the peak stress (during the first few per cent of axial strain). Little cracking or change in grain-size was observed in the samples which were not deformed beyond the strain level corresponding to the peak stress.

In the samples tested at a rate of $10^{-2} \mathrm{~s}^{-1}$, both grain boundary and individual intra-granular microcracks were visible by an axial strain of $2 \%$. With increasing strain, the intra-granular cracks developed a pattern of dense clustering within individual grains. These cracks were typically parallel to each other and persisted in these local areas to high strains. After these dense arrays of cracks began to form $(>4 \%)$, the grain-boundary cracks that formed in the initial stages of strain disappeared. These dense arrays of intra-granular cracks were not observed in test specimens deformed at the lower strain rate (Plate 3).

The larger remnant grains showed little internal cracking in samples deformed at both strain rates. In the highstrain-rate tests, the fine-grained material viewed between crossed polarizing filters corresponded with areas of dense fractures visible in the side-lit photographs (Plate $2 \mathrm{~b}$ and c). In contrast, the fine-grained material in the low-strainrate tests was significantly less fractured (Plate $3 \mathrm{~b}$ ) and showed no evidence of cracking above $4 \%$ strain.

\section{GONCLUSIONS}

This test program was undertaken to investigate and characterize damage in ice under triaxial stress conditions. Testing was performed by loading cylinders of fresh-water granular ice at a constant axial strain rate $\left(10^{-4} \mathrm{~s}{ }^{1}\right.$ or $\left.10^{-2} \mathrm{~s}^{-1}\right)$ at $-10^{\circ} \mathrm{C}$ under $20 \mathrm{MPa}$ confinement. Samples were loaded to endlevels of strain ranging from $0.4 \%$ to $28.8 \%$ true axial strain. The microstructural changes associated with increasing axial strain were characterized in thin sections of the deformed specimens and then compared with the mechanical behavior.

The peak stresses were, on average, 23.4 MPa for the $10^{2} \mathrm{~s}^{-1}$ strain-rate tests and 9.8 $\mathrm{MPa}$ for the $10^{-4} \mathrm{~s}^{-1}$ strainrate tests. The peak stresses corresponded to the strain level where both grain boundary and isolated intra-granular cracking initiated. With increasing strain, the dominant deformation was by dense intra-granular cracking at the high strain rate. Few cracks were observed at the low strain rate. The samples taken to the highest strains attained a relatively stable deviatoric stress at high strains, particularly for the tests done at $10^{-4} \mathrm{~s}^{-1}$.

A reduction in grain-size was observed in all the tests taken to strain levels greater than a few per cent. With that amount of strain, a texture developed that consisted of a few isolated large grains in a fine-grained matrix. Microcracking produced this effect in the samples tested at the higher strain rate. In the samples tested at the lower rate, however, there is little evidence of microcracking, suggesting that the mechanism of grain-size reduction is dynamic recrystallization. There is no significant grain-size reduction prior to $1 \%$ strain, indicating that these mechanisms become activated at approximately the peak stress level. Above 5-10\% strain, the average grain-size tends to stabilize at a lower value. This 
result is consistent with the work of Jacka and $\mathrm{Li}$ (1994) who identified a tertiary equilibrium grain-size in samples deformed to very high strains (at relatively low rates), which they interpreted as indicative of steady-state creep.

At the very highest strain levels in the higher-rate tests, there are regions which eventually become clear of cracks. This suggests that in fact a combination of crack healing and recrystallization may become a significant deformation mechanism in highly deformed samples, even at high strain rates in which cracking dominates initially.

These results support the work of Stone and others (1997) which indicated that prior stress history produces microstructural changes and increases in the deformation rate in ice. Stone and others (1997) investigated the impact of this damage on subsequent creep behavior of ice under moderate confinement and relatively low deviatoric stresses. Melanson (1998) and Meglis and others (1999) expanded that work to investigate the effects of prior damage on creep behavior of ice under the high-stress and high-confinement conditions associated with ice structure interaction.

\section{ACKNOWLEDGEMENTS}

Support for this research was provided by the Canada-Newfoundland Offshore Development Fund, the Natural Sciences and Engineering Research Council and the National Energy Board's Program on Energy Research and Development. The authors also gratefully acknowledge the use of facilities at the Institute for Marine Dynamics, National Research Council of Canada (NRC). The authors are grateful to R. E. Gagnon of the NRC and to P. Finlay andJ. Sweeney of Memorial University of Newfoundland for their contributions to this research. The authors thank the reviewers for their constructive and useful comments.

\section{REFERENCES}

Dieter, G. E. 1976. Mechanical metallurgy. New York, McGraw-Hill.

Frederking, R., I. J. Jordaan and J. S. McCallum. 1990. Field tests of ice indentation at medium scale, Hobson's Choice ice island, 1989. In IAHR. Symposium on Ice, Espoo, Finland, August 20-24, 1990. Proceedings. Vol. 2. Espoo, Helsinki University of Technology, 931-944.

Glen, I. F. and H. Blount. 1984. Measurement of ice impact pressures and loads onboard CCGS Louis S. St Laurent. In Lunardini, V. J., ed. Third International Offshore Mechanics and Arctic Engineering Symposium (OMAE), New Orleans, Louisiana, February 12-16 1984. Proceedings. Vol.3. New York, American Society of Mechanical Engineers, 246-252.

Jacka, T. H. and LiJun. 1994. The steady-state crystal size of deforming ice. Ann. Glaciol., 20, 13-18.

Jacka, T. H. and M. Maccagnan. 1984. Ice crystallographic and strain rate changes with strain in compression and extension. Cold Reg. Sci. Technol., 8(3), 269-286.

Johnston, M., K. R. Croasdale and I. J. Jordaan. In press. Localized pressure during ice structure interaction: relevance to design criteria. Cold Reg. Sci. Technol.

Jones, S. J. 1982. The confined compressive strength of polycrystalline ice. $\mathcal{F}$. Glaciol., 28 (98), 171-177.

Jordaan, I. J. and R. F. McKenna. 1988. Modelling of progressive damage in ice. In Saeki, H. and K.-i. Hirayama, eds. IAHR88. 9th IAHR International Symposium on Ice, 23-27 August 1988, Sapporo, Japan. Proceedings. Vol. 2. Sapporo, International Association for Hydraulic Research. Committee on Ice Problems, $585-624$.

Jordaan, I. J. and R. F. McKenna. 1991. Processes of deformation and frac- ture of ice in compression. In Jones, S. J., R. F. McKenna, J. Tillotson and I. J. Jordaan, eds. Ice-structure interaction. IUTAM-IAHR Symposium, S John's, Nezefoundland, Canada, 1989. Berlin, etc., Springer-Verlag, 283-309.

Jordaan, I. J., D. G. Matskevitch and I. L. Meglis. 1999. Disintegration of ice under fast compressive loading. Int. J. Fract., 97 (1-4), $279-300$.

Jordaan, I. J. and J. Xiao. 1993. Interplay between damage and fracture in ice structure interaction. In IAHR 92. 11th International Symposium on Ice, Banff, Alberta, Canada, June 15-19, 1992. Proceedings. Vol. 3. Edmonton, Alta, University of Alberta. Department of Civil Engineering, 1448-1467.

Jordaan, I. J., B. M. Stone, R. F. McKenna and M. K. Fuglem. 1992. Effect of microcracking on the deformation of ice. Can. Geotech. J., 29(1), 143-150.

Kachanov, M. 1997. Proper parameters of defect density for solids with cracks and cavities. In Inelasticity and damage in solids subject to microstructural change. Proceedings of the L.M. Kachanov Symposium. St John's, Nfld, Memorial University of Newfoundland, 47-72.

Kalifa, P., G. Ouillon and P. Duval. 1992. Microcracking and the failure of polycrystalline ice under triaxial compression. f. Glaciol., 38(128), 65-76.

Karr, D. G. and K. Choi. 1989. A three-dimensional constitutive damage model for polycrystalline ice. Mech. Mater, 8, $55-66$.

Kennedy, K. P., I. J. Jordaan, M. A. Maes and A. Prodanovic. 1994. Dynamic activity in medium-scale ice indentation tests. Cold Reg. Sci. Technol., 22(3), $253-267$.

Kheisin, D. E. and N.V. Cherepanov. 1973. Change of ice structure in the zone of impact of a solid body against the ice cover surface. Probl. Arct. Anlarct., 33-35, 239-245.

Kuehn, G. A., E. M. Schulson and W. A. Nixon. 1988. The effects of prestrain on the compressive ductile-to-brittle transition in ice. In Saeki, H. and K.-i. Hirayama, eds. IAHR88. 9th IAHR International Symposium on Ice, 2327 August 1988, Sapporo, Japan. Proceedings. Vol. 1. Sapporo, International Association for Hydraulic Research. Committee on Ice Problems, 109-117.

Meaney, R., S. Kenny and N.K. Sinha. 1991. Medium-scale ice structure interaction: failure zone characterization. In Muggeridge, D. B., D. B. Colbourne and H.M. Muggeridge, eds. POAC'91. The 11th International Conference on Port and Ocean Engineering under Arctic Conditions, September 24 28, 1991, St John's, Canada. Proceedings. Vol. 1. St John's, Nfld, Memorial University of Newfoundland. Ocean Engineering Research Centre, 126-140.

Meglis, I.L., P. M. Melanson and I. J. Jordaan. 1999. Microstructural change in ice: II. Creep behavior under triaxial stress conditions. 7. Glaciol., $45(151), 438-448$.

Melanson, P. M. 1998. Damage and microstructural change in laboratory grown ice under high pressure zone conditions. (M.Eng. thesis, Memorial University of Newfoundland.)

Mellor, M. and D.M. Cole. 1982. Deformation and failure of ice under constant stress or constant strain-rate. Cold Reg. Sci. Technol., 5(3), 201-219.

Muggeridge, K.J. and I.J. Jordaan. 1999. Microstructural change in ice: III. Observations from an iceberg impact zone. 7. Glaciol., 45 (151), 449-455.

Nadreau, J.-P. and B. Michel. 1987. Courbe intrinsèque de la glace en compression. 7. Phys. (Paris), 48, Colloq. Cl, 321-327. (Supplément au 3.)

Nordell, B. 1990. Measurement of $P-T$ coexistence curve for ice-water mixture. Cold Reg. Sci. Technol., 19(1), 83-88.

Rist, M.A. and S.A.F. Murrell. 1994. Ice triaxial deformation and fracture. 7. Glaciol., 40 (135), 305-318.

Rist, M.A., S.A.F. Murrell and P.R. Sammonds. 1988. Experimental results on the failure of polycrystalline ice under triaxial stress conditions. In Saeki, H. and K.-i. Hirayama, eds. IAHR88. 9th IAHR International Symposium on Ice, 23-27 August 1988, Sapporo, Japan. Proceedings. Vol. 1. Sapporo, International Association for Hydraulic Research. Committee on Ice Problems, 118-127.

Rist, M. A., S. J. Jones and T. D. Slade. 1994. Microcracking and shear fracture in ice. Ann. Glaciol., 19, 131-137.

Schapery, R. A. 1981. On viscoclastic deformation and failure behaviour of composite materials with distributed flaws. Adv. Aerospace Struct. Mater., AD-01, 5-20.

Stone, B. M., I. J. Jordaan, S. J. Jones and R. F. McKenna. 1989. Damage of isotropic polycrystalline ice under moderate confining pressures. In Axelsson, K. B. E. and L. A. Fransson, eds. POAC 89. The 10th International Conference on Port and Ocean Engineering under Arctic Conditions, June 12-16 1989, Lulea, Sweden. Proceedings. Vol. 1. Luleå, Tekniska Högskolan i Luleå, 408-419.

Stone, B. M., I. J. Jordaan, J. Xiao and S. J. Jones. 1997. Experiments on the damage process in ice under compressive states of stress. 7. Glaciol., $43(143), 11-25$. 